\title{
Jorge Millas. El valor de pensar
}

\section{Maximiliano Figueroa, Jorge Millas. El valor de pensar. Santiago: Ediciones Universidad Diego Portales, 2011.}

RIC ARDO SALAS

Universidad Católica de Temuco

Este importante libro de Maximiliano Figueroa recoge un riquísimo material acerca de muchas cuestiones que han agitado la vida sociopolítica en el Chile del siglo $\mathrm{xx}$, y dan sentido al título acerca del pensar comprometido y vigilante presente en la obra del filósofo chileno Jorge Millas (I9I7-I982). Se trata de un libro de filosofía no porque aluda a las peripecias de un filósofo, sino porque desenvuelve las principales ideas y argumentos que se esgrimieron en tiempos de profunda transformación social y política de Chile, particularmente entre los años I960 y I980. La agudeza de la interpretación de Figueroa permite demostrar cómo se construye el pensar crítico de un filósofo chileno y permiten mostrar una otra mirada para entender los conflictos de ese tiempo a partir de las ideas en pugna. En particular es una obra relevante porque se analizan aquí los textos ligados a los últimos años de la vida de Jorge Millas, entre I973 y I982, donde aún falta por indagar específicamente el papel de la filosofía en la universidad y de los filósofos. Millas fue una de las pocas voces intrépidas y discordantes que se atrevieron a analizar en profundidad los problemas que vivía la sociedad chilena y ofrece un testimonio de las conse- 
cuencias de un pensar a contracorriente, en tiempos que muchos intelectuales optaron por el silencio y la sumisión.

En este sentido, el pensar crítico y vigilante de Millas permiten entender con mayor cabalidad las ideas en pugna en años marcados por la gran politización y crisis de la sociedad chilena y que se hizo sobre todo eco en los movimientos estudiantiles universitarios. Estos textos que se entregan de Millas ofrecen una lectura de los fenómenos sociales que afectaron las universidades chilenas y permiten ofrecer un cuadro de la mirada que la universidad tiene de ella misma. Pero sobre todo este pensar solitario de Millas da cuenta de la evolución de lo que acontece en las ideas en los últimos dos gobiernos democráticos y de un preciso análisis de la intervención militar que impuso una mordaza al pensamiento libre y crítico de sus académicos. El libro se vuelve muy relevante para entender la politización y la despolitización de la universidad pública y el modo de hacerla funcional al ritmo de un nuevo modelo de sociedad, y que se hace patente hasta nuestros días en la defensa de la universidad pública, debilitada por casi tres décadas de auge de las universidades privadas.

El análisis del pensar social de Millas es relevante además para la historia del Chile contemporáneo ya que permite establecer hilos conductores de un tiempo de rupturas estructuarles. Donde un cierto análisis insiste aún en los quiebres y rupturas radicales en el año 1973, en estos textos se observa a un académico prestigioso abogando por la racionalidad, el diálogo y el respeto de las personas, y dejando en evidencia el bajo espesor moral de los interventores militares de la universidad.

El rico material heterogéneo y a veces inédito permiten entender el desarrollo de un pensamiento crítico tan ligado a los contextos de los procesos de la «reforma» en los tiempos de los presidentes Frei y Allende, y a la «intervención militar de la universidad». En ambos procesos se deja en evidencia la valentía de un pensador discordante con las ideas masivas en boga entre los intelectuales y los estudiantes. Todos los textos demuestran que la filosofía tuvo en la obra de Millas la capacidad de pensar en su mayor hondura un tiempo de quiebres y queda como un testigo de complicidades y mudo pensar de otros académicos que prefirieron las prebendas del poder.

A través de la construcción del pensar vigilante de Millas, el autor busca entender cómo la filosofía puede aportar con este instrumental analítico y crítico que es el suyo, profundizar la situación de la universidad en la complejidad sociohistórica de su tiempo, y entrega argumentos para distinguir la filosofía y la ideología. 
El prólogo del libro se concentra en mostrar la praxis reflexiva de este pensador, mostrando que Millas pensó y ejerció como pocos la tarea pública que se espera del intelectual. Dotado desde joven de una capacidad oratoria llevará esta capacidad a pensar con sentido humanista crítico y reflexivo a los grandes temas que afectan a la sociedad actual y a la institución que debe promover el saber más riguroso. En el libro se exponen cinco temas vectores: la tarea del intelectual, filosofía y violencia, democracia y derechos humanos, el neoliberalismo de Hayek y la idea de la universidad. Veamos muy sucintamente cada uno de ellos.

En la tarea del intelectual, Millas postula que el aporte del intelectual es despertar a las gentes de «una existencia sonanbúlica». En un texto escrito para el premio Ricardo Latcham, indica que el escritor exhorta a los individuos a pensar por sí mismos para que se dispongan de un modo más lúcido y activo frente a la vida. Se trata de construir, según Millas, una sociedad reflexiva, es decir «una sociedad que asuma la historicidad propia como condición exigida por la deliberación pública que ha de guiar la definición del destino». En este pensar crítico, no sólo cuestionará las ideas del marxismo ideológico por su dogmatismo, y de un grupo de elegidos que creen tener el secreto de la situación histórica, sino también a las ideas antimarxistas que esconden a los detractores de la democracia.

La filosofía y violencia es un tema central que cruza desde muy temprano el pensar de Millas, en su defensa del pacifismo en el año 38 y sobre todo en su Idea de la filosofía (I970), la filosofía es presentada como alternativa crítica a la posibilidad de la violencia y al sometimiento intelectual que los discursos ideológicos suelen implicar. Para Millas, comprender la filosofía de la violencia supone partir desde el dolor y sufrimiento de las víctimas. La violencia pone en relación lo fáctico y lo ético en el curso de la historia, y muestra las contradicciones a la que es llevado el militante de una causa revolucionaria por la que se infringe violencia y sufrimiento a otros.

La democracia para Millas no representa solo un sistema de valía procedimental, sino, de un modo fundamental, un régimen con implicancias sustanciales, como un auténtico proyecto político que compromete la construcción moral de la sociedad. Figueroa destaca tres aspectos esenciales de la democracia: como forma de convivencia, como desideratum y como riesgo. Los derechos humanos constituyen una de las condiciones de posibilidad para la propia realización de la sociedad democrática.

El neoliberalismo de Hayek se construye a partir de deficiencias éticas y teóricas que desde muy temprano fueron advertidas por Millas en su crítica a 
un concepto de libertad como ausencia de coerción, lo que implica cuestionar la idea del mercado como garante sin mas de la libertad. Por esta vía las ideas del pensador austriaco hacen una incompleta consideración de la libertad humana. Para entender adecuadamente la libertad es menester profundizar la naturaleza humana como tal, las particularidades individuales que dimanan de ella y la existencia de la sociedad humana. El error de Hayek es la intencionalidad ideológica: «No es la libertad la que sirve de medida al capitalismo, sino éste a aquélla».

La idea y defensa de la universidad son los textos más interesantes desde la perspectiva de la experiencia vital de Millas. Se trata de entender que la universidad tiene una reflexividad previa que parte de su naturaleza propia y de su responsabilidad. Como lo afirma Millas tajantemente: «Antes que nada la universidad tiene que ser baluarte del conocimiento inspirado en la verdad y en la libertad y regulado por la discusión crítica» (203). La universidad tiene que asumir el desafío de una sociedad de masas, pero la universidad no puede masificarse. Por ello, Millas entiende desde muy temprano que en una sociedad de masas más individuos presionarán por tener participación en el poder y la conducción del destino social, pero eso no puede llevar a que la comunidad universitaria pierda las funciones de cada miembro, y de ahí el rechazo de Millas a que los estudiantes intervengan directamente en el gobierno universitario. Por eso Millas se opuso a la politización de la universidad ya que la desnaturaliza, porque pone en jaque la ciencia y la crítica.

A lo largo de este texto se constata la agudeza y la valentía del filósofo Millas, quien no claudicará en su defensa del pensar filosófico crítico y riguroso, a contracorriente de las ideas de los movimientos sociales y políticos en boga, que apelan a deconstruir ideas no suficientemente reflexionadas. La adecuada interpretación de los textos de Millas le permite a Figueroa situarlo como uno de los filósofos críticos y polemistas que asumieron el rigor del pensar filosófico de cara a su tiempo. Se trata de un pensar vigilante que no es repetición ni mera asunción de lo que se ha elaborado por otros filósofos en otros contextos. En otras palabras, este libro permite profundizar aspectos de la filosofía de Millas y entrega el sentido y el valor del pensar filosófico en tiempos de crisis. Cobra pleno sentido la idea de alguien que quiso ser «irremediablemente, filósofo», como lo destaca el prologuista Humberto Giannini. Ser «irremediablemente, filósofo» es captar la labor sistemática de un pensador que llevó a «todas partes su pensamiento vigilante, insobornablemente reflexivo y ético por el que se caracterizó toda su vida» (I7). 